\title{
UM RELATO DE EXPERIÊNCIA DE ENSINO REMOTO DURANTE A PANDEMIA DA COVID-19: PLANEJAMENTO E EXECUÇÃO
}

DOI: 10.37702/2175-957X.COBENGE.2021.3584

Luciana Torres Correia de Mello - lucianatcmello@yahoo.com.br UFERSA

Rua Lucia Viveiros 649

59086-005 - Natal - RN

Richardson Bruno Carlos Araújo - acbr2015@gmail.com UFERSA

Rua Princesa Isabel 330

59012-400 - Natal - RN

Resumo: A pandemia do Coronavírus impôs mudanças em todos os âmbitos da sociedade. Assim, a educação, em todos os seus níveis, passou por diversos decretos que, em um primeiro momento, suspendeu as atividades presenciais e, posteriormente foram retomadas na modalidade remota. Dessa forma, os docentes, discentes e ambientes de ensino passaram por uma série de obstáculos a fim de conciliar a urgência de implantação do período, a ausência de planos de contingência e uma realidade pandêmica. Nesse contexto, este artigo, de abordagem qualitativa, apresenta um relato de experiência do ensino remoto em uma disciplina do curso de Engenharia de Produção da Universidade Federal Rural do Semi-Árido com foco no plano de curso de um componente curricular e aspectos vivenciados no período. Para isso são apresentadas as diferenças entre Educação à Distância, ensino remoto, variáveis de planejamento e metodologias para o ensino remoto. $O$ relato detalha o planejamento e execução da disciplina, explanando sobre a preparação, o plano de curso, ferramentas de ensino utilizadas, bibliotecas virtuais, métodos avaliativos, momentos síncronos e assíncronos. Os aspectos positivos da experiência foram a ausência de trancamentos, realização de visita técnica online e a praticidade de correção de provas e tarefas no sistema institucional. Em contrapartida, as principais dificuldades foram a sobrecarga de trabalho ao docente, a dificuldade inicial de adaptação com a ausência de quadros para ilustrar as explicações e principalmente a redução de participação dos alunos no decorrer das semanas, principalmente pelo microfone. 


\section{COBENCE \\ $2021 \begin{aligned} & \text { eIV Simpósio Internacional } \\ & \text { de Educação em Engenharia } \\ & \text { da ABENGE }\end{aligned}$ 28 a 30 de SETEMBRO \\ Formação em Engenharia: Tecnologia, Inovaçáo e Sustentabilidade"}

Palavras-chave: Ensino Remoto. Relato de experiência. Planejamento de aula. 


\section{UM RELATO DE EXPERIÊNCIA DE ENSINO REMOTO DURANTE A PANDEMIA DA COVID-19: PLANEJAMENTO E EXECUÇÃO}

\section{INTRODUÇÃO}

Em março de 2020, chegou ao estado do Rio Grande do Norte (RN) a confirmação dos primeiros casos de contaminados pelo vírus da COVID-19 (RIO GRANDE DO NORTE, 2020). Era a pandemia iniciada na Ásia no final do ano de 2019, com o primeiro caso confirmado, no Brasil, em fevereiro do ano de 2020. A partir daquele momento, as atividades que geravam aglomeração de pessoas foram suspensas na maioria dos municípios brasileiros. Entre essas atividades, o Decreto ํㅜ 29.524, de 17 de março de 2020 suspendeu o ensino presencial nas redes pública e privada em todo o estado do Rio Grande do Norte.

Em contrapartida, no dia 28 de abril de 2020, o Conselho Nacional de Educação (CNE) autorizou a oferta de atividades não presenciais em todas as etapas de ensino, desde a educação infantil até o ensino superior, por meio do parecer CNE/CP nำ 5/2020 (MEC, 2020). O documento também versava acerca de orientações para carga horária e dias letivos, como alternativa para que as atividades de ensino pudessem continuar.

Nesse momento, iniciou-se uma busca, pelas instituições de ensino, de alternativas de ajustamento a essa nova realidade de forma a não comprometer as atividades de ensino/aprendizagem. Era uma busca para instaurar o ensino remoto emergencial. A aprendizagem dos alunos começou a ser pensada e planejada com cuidado para tentar garantir que todos tivessem direito ao processo de aprender e de que as metodologias utilizadas não causassem diferenças de oportunidades de acesso ao ensino (SILVA; GOULART; CABRAL, 2021).

Em face da urgência na implantação do ensino remoto por essas instituições de ensino que, em maioria, não estavam acostumadas e adaptadas a esse formato de ensino, havia necessidade mínima de planejamento das ações. O planejamento tinha que acontecer pelas instituições, pensando e operacionalizando sistemas, softwares, ferramentas, acesso dos estudantes e afins, que permitisse o contato remoto entre 0 docente e o discente; e pelos docentes, que tinham que utilizar de diferentes ferramentas, metodologias de ensino, formas de avaliação, formato de registro de presença, entre tantas outras situações, para incluir e permitir que o seu aluno fosse contemplado com 0 aprendizado. O planejamento institucional e docente foi pensado para que o estudante conseguisse se adaptar àquele novo formato.

Em algumas instituições, o ensino remoto iniciou no meio de um semestre conturbado, cheio de indecisões e aconteceu com semestres excepcionais ou emergenciais (APPENZELLER et al., 2020). Assim, na Universidade Federal Rural do Semi-Árido (UFERSA) localizada em municípios do interior do RN, um novo semestre (2020.3) estava iniciando com esse novo formato (Resolução CONSEPE/UFERSA no 002/2020). Esse semestre excepcional ou emergencial se tornou opcional para os discentes e representou uma "oportunidade" de planejar, organizar e sentir, na prática, como seriam as aulas no novo formato. Também foi uma ação "teste" para saber se o próprio docente se adaptava, ou não, àquelas condições postas no planejamento e se os estudantes se adaptavam e obtinham bons resultados de aprendizagem naquelas metodologias.

Este artigo trata do relato de experiência do ensino remoto em uma disciplina do curso de Engenharia de Produção da UFERSA. Antes do relato em si, o artigo traz um embasamento teórico sobre os temas ensino remoto e metodologias sugeridas (seção 2) e, a explanação sobre o método de pesquisa (seção 3). O relato em si é apresentado (seção 
4) nos aspectos de planejamento e execução no decorrer da disciplina. Ao final do artigo (seção 5) são descritos os aspectos que se sobressaem no relato, que poderão contribuir para docentes que desejarem conhecer um pouco sobre o ensino remoto na pandemia.

\section{O ENSINO REMOTO DURANTE A PANDEMIA}

Faz-se necessário, para fins de esclarecimentos de conceitos e definições, maior discussão acerca dos temas ensino remoto versus $\mathrm{EaD}$ (2.1), seu planejamento (2.2) e sobre as metodologias utilizadas e sugeridas pela literatura (2.3).

\subsection{O ensino remoto $X$ Ensino à Distância}

O conceito de aprendizado à distância não é novo, mas considera-se que foi o acesso à internet que, efetivamente, contribuiu para a expansão de cursos à distância (ELMÔR FILHO et al., 2019). A partir de então, essa possibilidade é aproveitada oficialmente, por meio do Ensino à Distância $(\mathrm{EaD})$ e, agora, adaptadas para o ensino remoto, nesse momento de suspensão de aulas presenciais.

Mas, é importante diferenciar a modalidade de Ensino à Distância $(E a D)$ e as atividades remotas de ensino. $\mathrm{O} E \mathrm{ED}$ é uma modalidade regulamentada, com funcionamento que requer a concepção didático-pedagógica, estruturado com estratégia pedagógica pré-definida e contemplando todo o processo avaliativo discente. Já as atividades remotas de ensino, foram adotadas para suprir as aulas presenciais devido ao isolamento social imposto pela pandemia, se constituem como uma atividade pedagógica temporária e adotada, na maioria das vezes, via internet (NOGUEIRA et al., 2020).

O ensino remoto foi um ajuste temporário e emergencial, por isso, tão difícil de ser implementado, pois, muitas vezes, as instituições de ensino não possuem infraestrutura e recursos tecnológicos adequados, os professores não são qualificados e formados para a docência em meios digitais, tampouco possuem conhecimentos para adaptarem seus materiais para disponibilização nos ambientes virtuais. Além disso, os estudantes podem não terem os equipamentos necessários em casa (SILVA; GOULART; CABRAL, 2021). Ao contrário, o EaD é estruturado para atuar por meio de plataformas virtuais, com preparo e conhecimento dessas metodologias pelos docentes e discentes.

Assim, o ensino remoto necessita de uma mediação didático-pedagógica que faz uso das ferramentas tecnológicas e digitais entre professores e estudantes, promovendo atividades educativas em lugares ou tempos diversos, assumindo momentos síncronos e/ou assíncronos (FUCKNER, 2020).

\subsection{O planejamento de aulas para o ensino remoto}

O planejamento tem uma importância fundamental do ponto de vista pedagógico e operacional na medida em que tem implicações na forma como o estudante aprende (ELMÔR FILHO et al., 2019). Para o docente, o ato de planejar é um momento importante porque permite que ele entre em contato com a teoria, compreendendo o seu espaço educativo e a prática pedagógica, como um processo sistematizado que auxilia no preparo das atividades garantindo maior eficiência para que, em um prazo determinado, consiga alcançar os objetivos de aprendizagem (BAZANI; MIRANDA, 2018).

É importante o planejamento da disciplina, curso ou aula antes da seleção das ferramentas digitais e metodologias de ensino a serem utilizadas. Para isso três etapas são fundamentais. A primeira, é planejar a disciplina com foco no objetivo educacional. Nesse momento são avaliados os conteúdos para aprendizagem do aluno, as competências e habilidades que precisam ser aprendidas e os objetivos principais - não existindo grandes 
diferenças do ensino presencial. Na segunda etapa é importante selecionar a ferramenta mais adequada para cada conteúdo e habilidade. Já na terceira, é elaborado o conteúdo para o aluno (NOGUEIRA et al., 2020).

A participação dos professores no planejamento é essencial pois eles tiveram seus planos de ensino alterados (NOGUEIRA et al., 2020). O plano de ensino é um instrumento elaborado pelos professores, em cada disciplina que ministra, e é utilizado como norteador da prática docente, compreendendo a estruturação dos objetivos educacionais, conteúdos abrangidos, metodologias de ensino e formas e instrumentos de avaliação (BAZANI; MIRANDA, 2018).

Apesar de constar, no plano de curso, o mesmo conteúdo programático no ensino remoto ou presencial, a forma como este será exposto ao aluno, é diferente de como estava-se acostumado no ensino presencial e, igualmente diferente do que é utilizado no EaD. Os docentes, na maioria das instituições de ensino, precisariam estar de forma síncrona com seu aluno, em algum momento de aula, fosse para expor conteúdo ou para tirar dúvidas e fazer esclarecimentos.

Recomenda-se que o plano de curso seja mais claro e completo possível, para docente e discente, relatando aspectos de metodologia de ensino, formato de aulas, materiais utilizados, tarefas e atividades, datas e cronogramas, entre outros. Para o ensino remoto, a divisão e esclarecimento quanto aos momentos síncronos e/ou assíncronos, também deve estar no plano de curso para que o discente tenha conhecimento, exatamente, das atividades que ele deverá realizar. Esse detalhamento e cuidado auxiliam para que os imprevistos (problemas com falta de energia e internet, motivos familiares e de doenças, dificuldades com os equipamentos eletrônicos etc.) não atrapalhem e prejudiquem o aprendizado do discente.

É importante destacar que em qualquer planejamento de curso e/ou aula, presencial ou remoto, é possível que sejam feitos ajustes no decorrer da disciplina a fim de torná-la mais próxima à realidade e atenda à necessidade e interesse dos discentes (BAZANI; MIRANDA, 2018). No ensino remoto excepcional ou emergencial, isso está ainda mais presente, já que é a "primeira" experiência do docente e discente.

\subsection{Metodologias para o ensino remoto}

É possível que a primeira dúvida surgida ao decidir sobre as metodologias de ensino a serem utilizadas no ensino remoto é se são as mesmas utilizadas no EaD ou no ensino presencial. Não necessariamente as mesmas ferramentas serão úteis, visto que podem não serem adequadas ao migrar para uma plataforma virtual, como por exemplo exercícios em sala de aula, em grupo (MACHADO, 2020), jogos com estrutura física, laboratórios, entre outros. O Conselho Nacional de Educação, ao autorizar atividades de ensino não presenciais, falou sobre possíveis formatos, como a utilização dos meios digitais (vídeo aulas, conteúdos organizados em plataformas virtuais de ensino e aprendizagem, redes sociais, correio eletrônico, blogs, entre outros), por meio de programas de televisão ou rádio; pela adoção de material didático impresso e distribuído aos alunos e/ou responsáveis, ou ainda pela orientação de leitura, projetos, pesquisas, atividades e exercícios indicados nos materiais didáticos (MEC, 2020).

De maneira geral, os alunos e os professores necessitam se adaptar a esta nova situação, aprendendo a utilizar novas estratégias e ferramentas, e rever materiais para estas novas plataformas, assim como as formas de ensinar (MACHADO, 2020). Os docentes, pegos de surpresa, foram em busca de tutoriais, livros, materiais on-line sobre como gravar vídeos e áudios, como fazer uma aula on-line, entre outros.

Considerando o uso de momentos síncronos e assíncronos durante o aprendizado nos ambientes virtuais, é importante selecionar ferramentas ou metodologias específicas. 
Salienta-se que os momentos síncronos, são aqueles em que o docente e discente dividem uma sala de aula virtual, em tempo real, e os momentos assíncronos são aqueles cuja interação entre participantes (professores e alunos) não necessariamente ocorre ao mesmo tempo (SANTOS JUNIOR; MONTEIRO, 2020).

No primeiro momento, a decisão é sobre a ferramenta utilizada no ambiente de ensino virtual, ou seja, os Ambientes Virtuais de Aprendizagem (AVAs) (NOGUEIRA et al., 2020). AVAs são sistemas de gerenciamento de conteúdo e aprendizagem com contextos híbridos de educação presencial e à distância (ANJOS, 2012). Há diversos tipos de AVA no Brasil e entre eles o mais utilizado é o Moodle $\AA$, visto que é um software livre que pode ser instalado nos sites de instituições de ensino sem a necessidade de pagamento. O Google Classroom® também é uma alternativa como recurso gratuito utilizado nos ambientes de ensino. Nos quais podem ser disponibilizados materiais e atividades para os estudantes (NOGUEIRA et al., 2020; SANTOS JUNIOR; MONTEIRO, 2020). Além desses, instituições podem utilizar sistemas próprios. Essa decisão deve estar alinhada entre o docente e a instituição de ensino, em busca da padronização para que o estudante não se perca em meio a tantas opções (NOGUEIRA et al., 2020).

Para os momentos síncronos são conhecidas as ferramentas Google Hangout®, Zoom® (SANTOS JUNIOR; MONTEIRO, 2020), Microsoft Teams®, Google Meet®, WhatsApp® (BLAUTH; DIAS; SCHERER, 2019) e Skype®. A escolha da ferramenta deve estar alinhada com o docente e instituição, além de considerar as configurações de limite máximo de pessoas (NOGUEIRA et al., 2020).

Para os momentos assíncronos, de atividades pré-aula ou pós aula, poderão ser escolhidos fóruns de discussão (BLAUTH; DIAS; SCHERER, 2019), lista de discussão, enquetes, leituras ativas, entre outras. O recurso escolhido deve permitir a realização das atividades. Assim, algumas ferramentas poderão ser úteis para esse contato, que também pode acontecer no próprio AVA, se assim for permitido. Outras também podem ser utilizadas como Google Docs ${ }^{\odot}$ e Kahoot! ${ }^{\circledR}$ (FONTES et al., 2020).

\section{MÉTODO DE PESQUISA}

Este trabalho tem como método de pesquisa o estudo de caso, que trata do relato de experiência do ensino remoto em uma disciplina do curso de Engenharia de Produção da UFERSA durante o período de pandemia da COVID-19. Utiliza-se de uma abordagem qualitativa porque faz inferências, interpretações e reflexões a respeito do relato. O estudo de caso qualitativo permite avaliar fenômenos reais e compreender informações detalhadas a respeito do acontecimento (YIN, 2015).

O relato aqui trazido aconteceu na disciplina Gestão da Manutenção e Confiabilidade, do curso de Engenharia de Produção da UFERSA no Rio Grande do Norte. Essa disciplina foi ministrada no período de junho a julho de 2020, durante o semestre suplementar excepcional 2020.3 implementado pela referida instituição. Para melhor entendimento, a próxima seção (4. O relato do caso) traz detalhes de planejamento e execução.

\section{O RELATO DO CASO}

Essa seção detalha o relato de experiência abordado em dois momentos: 4.1 planejamento e 4.2 execução. 


\subsection{Planejamento}

Antes de serem iniciadas as atividades de ensino remoto, a universidade organizou um período oficial de planejamento das atividades. Nesse espaço, os docentes poderiam participar de seminários oficiais oferecidos pela instituição e buscar outros, além de se dedicarem à construção da disciplina nesse novo formato. Como tratava-se da primeira experiência, cada professor ficou com apenas uma disciplina e o semestre teria duração de seis semanas, isso permitiria que as aulas acontecessem com frequência diária. Alguns dos cursos buscado para conhecer um pouco mais sobre o tema, estavam: "Implicações, alternativas e ações para atividades acadêmicas no período de pandemia"; "Metodologias ativas de aprendizagem"; "Adoção forçada da tecnologia durante a pandemia"; "De repente, professor on-line"; "Revolucionando a sala de aula on-line com metodologias ativas".

O planejamento das atividades de aula compreendeu os seguintes aspectos: metodologia utilizada, programação de atividades, material utilizado (acesso) e plano de aulas detalhado com conteúdo e datas - descrito no documento de plano de curso. Além dessas informações, o documento continha informações sobre objetivos do curso, formato de avaliação, entre outros. O modelo foi disponibilizado pela instituição e ficava a cargo do professor o roteiro detalhado.

A metodologia utilizada foi de encontros síncronos com duração de 1,5 horas durante os 5 dias da semana, utilizando a plataforma Google Meet ${ }^{\circledR}$. O material de aula era previamente disponibilizado pelo AVA da instituição, o Sistema Integrado de Gestão de Atividades Acadêmicas (SIGAA) e, ao final das aulas, era disponibilizado um link para a Lista de Frequência. Em relação à programação das atividades, além das aulas expositivas com discussão de textos, também foram utilizados fóruns de discussão, tarefas semanais e atividades avaliativas por meio de questionário no sistema próprio da instituição.

A programação foi realizada considerando planejamento das atividades e a duração das unidades (estabelecido pela instituição), cada uma com 2 semanas. Assim foi disponibilizado aos discentes no primeiro dia de aula o planejamento detalhado, como ilustra a Figura 1, a fim de auxiliar os discentes na preparação e planejamento do período excepcional.

Figura 1 - Planejamento detalhado

\section{Semana 1}

\begin{tabular}{|l|l|}
\multicolumn{1}{|c|}{ Dias } & \multicolumn{1}{c|}{ Conteúdo } \\
\hline $2^{\text {a }}$ feira $-15 / 06$ & Apresentação da disciplina e das ferramentas \\
\hline $3^{\text {a }}$ feira $-16 / 06$ & Conceitos iniciais \\
\hline $4^{\mathrm{a}}$ feira $-17 / 06$ & Discussão atividade + Classificação e tipos de manutenção \\
\hline $5^{\mathrm{a}}$ feira $-18 / 06$ & Tipos de manutenção - Corretiva \\
\hline $6^{\mathrm{a}}$ feira $-19 / 06$ & Tipos de manutenção - Preventiva \\
\hline Sab (20/06) $23: 59$ & $1^{\text {a }}$ ENTREGA - Envio da Tarefa 1 via Sigaa e Participação no Fórum 1 \\
\hline
\end{tabular}

Semana 2

\begin{tabular}{l|l}
\multicolumn{1}{c|}{ Dias } & \multicolumn{1}{c}{ Conteúdo } \\
\hline $2^{\text {a }}$ feira $-22 / 06$ & Tipos de manutenção - Preditiva \\
\hline $3^{\text {a }}$ feira $-23 / 06$ & Tipos de manutenção - Produtiva \\
\hline $4^{\text {a }}$ feira $-24 / 06$ & Atribuições e funções \\
\hline $5^{\text {a }}$ feira $-25 / 06$ & Resolução de exercícios \\
\hline $6^{\text {a }}$ feira $-26 / 06$ & Prova 1 $^{\text {a }}$ Unidade \\
\hline Sab (27/06) 23:59 & $2^{\text {a }}$ ENTREGA - Envio da Tarefa 2 via Sigaa e Participacão no Fórum 2
\end{tabular}

Fonte: Dados da pesquisa (2021) 
As unidades eram compostas por duas tarefas, dois fóruns de discussão e uma atividade avaliativa maior, e juntas, com o somatório de 10 pontos, iriam compor a nota da referida unidade. Apenas a $3^{\underline{a}}$ unidade foi diferente em virtude de um trabalho apresentado. Esse trabalho buscava "aplicação" do conteúdo teórico visto no decorrer da disciplina. Como em momento de distanciamento pela pandemia da COVID-19 não seria viável a realização do trabalho in loco, os discentes ficaram livres para buscar uma aplicação online ou realizar uma análise de algo exposto na internet. A Figura 2 ilustra a distribuição das atividades e notas nas unidades da disciplina.

Figura 2 - Divisão das atividades por unidade

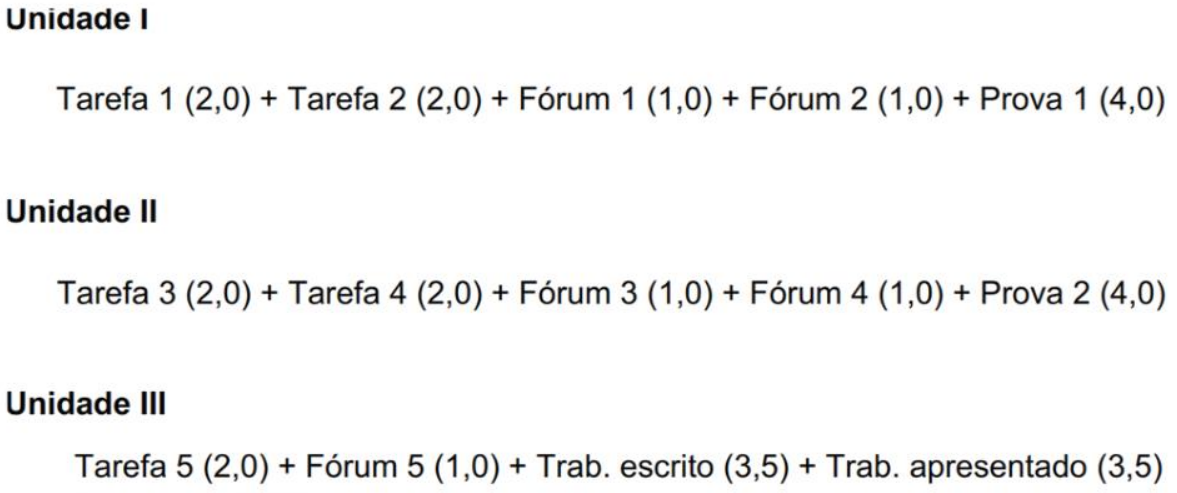

Fonte: Dados da pesquisa (2021)

Com a disciplina preparada, planejada e apresentada aos alunos para que também se planejassem e estivessem aptos a cursar a disciplina com êxito, a próxima etapa é a vivência do período remoto excepcional.

\subsection{Execução}

O semestre foi iniciado com a "aula inaugural" no primeiro dia, para explicar a metodologia da disciplina, apresentar o plano do curso, e repassar informações e esclarecimentos a respeito das atividades avaliativas e cronogramas. Ainda, neste encontro foram realizados testes com as ferramentas (Figura 3) e com a biblioteca virtual para garantir o entendimento e acesso de todos.

Figura 3 - Testes com ferramentas

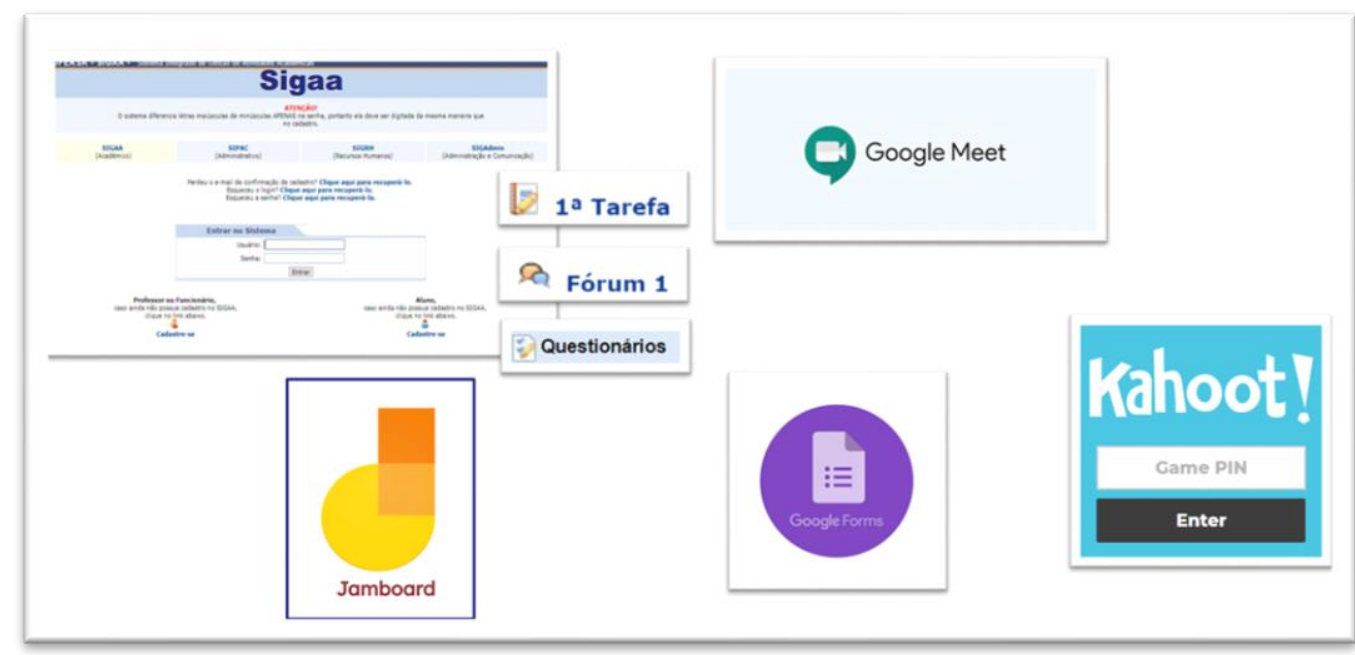

Fonte: Dados da pesquisa (2021) 
No suporte bibliográfico, as bibliotecas virtuais do SIGAA e da Pearson foram apresentadas, como também a operacionalização e funcionalidades que facilitam 0 aprendizado como grifos, retomar na página que parou, anotações etc. O conteúdo da disciplina foi adaptado aos exemplares disponíveis. Assim, ao final das aulas era informado aos alunos as páginas dos livros referentes ao conteúdo abordado no momento síncrono, como continuação do processo ensino-aprendizagem. A Figura 4 mostra a organização dos materiais (livros) a serem utilizados no decorrer do semestre, como códigos (Livro A, B, C e D) para facilitar a visualização no plano detalhado das aulas.

Figura 4 - Acervo digital disponível para os alunos

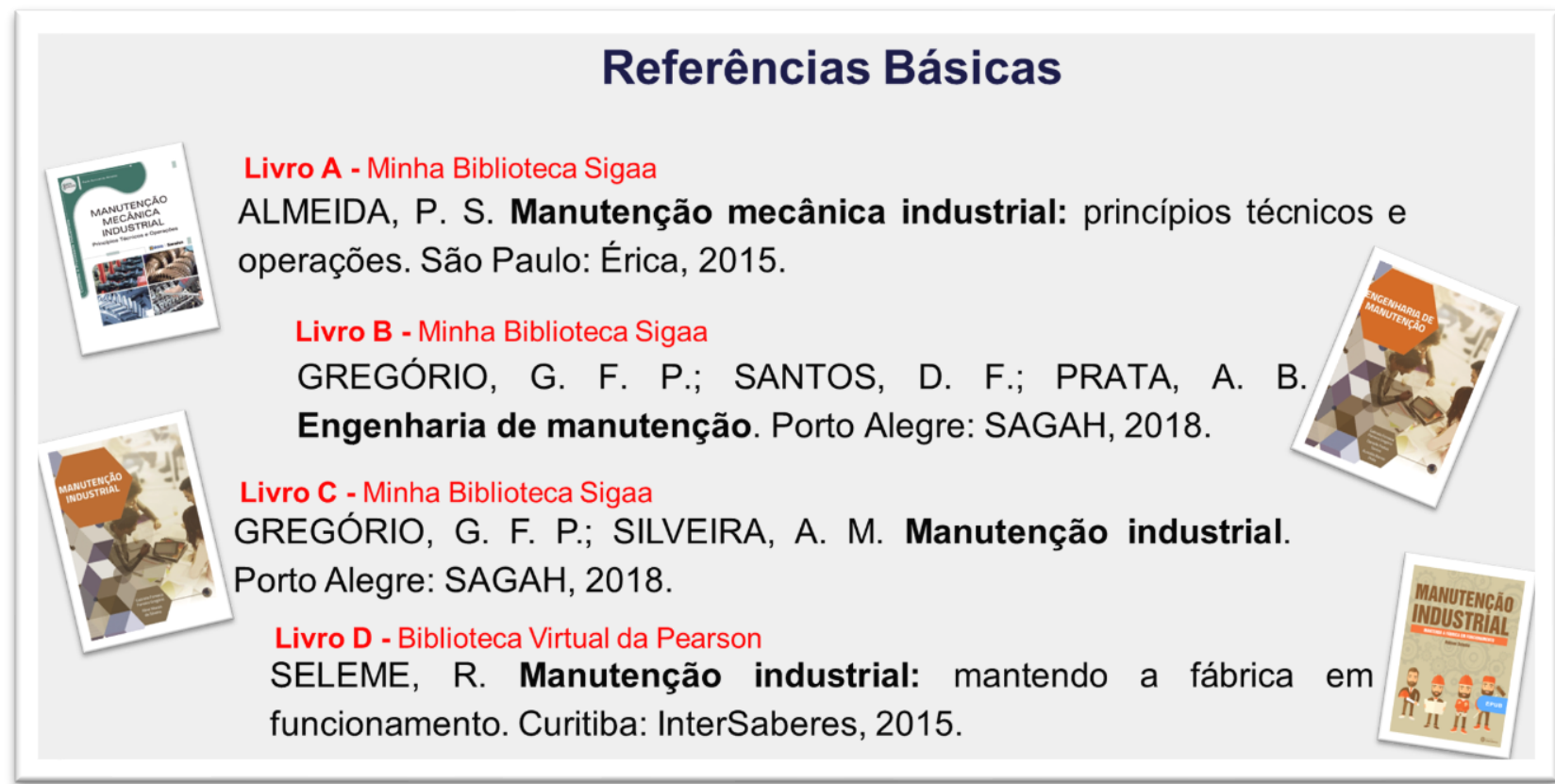

Fonte: Dados da pesquisa (2021)

Antes de iniciar as aulas também foram passadas informações e recomendações para um melhor aproveitamento, como exposto na Figura 5. E salientado, que em caso de não poder utilizar o microfone, o chat da plataforma poderia ser utilizado durante toda a aula.

Figura 5 - Recomendações iniciais

1 Utilize fones de ouvido , se lhe for mais conveniente.

2 Tenha um caderno para tomar nota de temas importantes.

3 Mantenha microfone desabilitados enquanto não estiver falando

4 Utilize a ferramenta "Nod Reaction' 슬 para interromper a aula.

5 Assine a lista de presença no momento oportuno

Fonte: Dados da pesquisa (2021) 
Durante a realização das atividades tipo tarefa semanal, inicialmente planejada para serem realizadas de forma individual, percebeu-se um nível de similaridade muito grande entre os discentes, fato este que precisou de uma adaptação no planejamento. Por isso, a atividade passou a ser realizada em dupla.

Outro elemento de ensino assíncrono, foi a realização de fóruns, nos quais o aluno tinha que respondê-lo e interagir nas respostas dos colegas. A prática acabou por motivar a discussão do conteúdo com temas contemporâneos, visto a participação/frequência de comentários associados a uma resposta. Como prática docente, eram dados feedbacks para as respostas dos alunos, levantando pontos de discussão e reflexão às contribuições individuais dos alunos.

Ao final da disciplina, foi desenvolvido e aplicado um questionário simples que buscava compreender a percepção dos alunos nessa nova experiência de ensino remoto. Vale salientar que a própria instituição já disponibilizava ao fim do semestre um questionário que buscava compreender a percepção dos estudantes durante as disciplinas vistas naquele semestre. Neste semestre, a docente buscou entender opiniões específicas a respeito da metodologia utilizada, além da impressão sobre aspectos gerais do novo formato. Por isso, eram questionários com objetivos distintos.

\section{$5 \quad$ CONCLUSÕES}

É importante salientar que a experiência relatada neste artigo tem como foco o relato do ensino remoto durante a pandemia da COVID-19, especialmente no planejamento do plano de curso. Mas, ressalta-se a importância de outros níveis de planejamento educacional, como o institucional e curricular.

Sobre esse relato, após a experiências, podem ser destacados aspectos positivos e algumas limitações. Como pontos positivos destacam-se, não houve trancamentos dos alunos no decorrer do semestre, a visita técnica on-line e a praticidade na correção das tarefas e provas que foram realizadas pelo sistema próprio da instituição.

Em contrapartida, as principais dificuldades e limitações foram em relação as atividades semanais, que geraram maior carga de trabalho ao docente, além da dificuldade inicial de adaptação com a ausência de quadros para ilustrar as explicações. Lembrando que a utilização das ferramentas físicas corretas, como uma mesa digitalizadora e mais de uma tela de monitor, talvez pudessem solucionar essas dificuldades. O maior destaque de limitação e dificuldade, do formato remoto, foi a redução de participação dos alunos no decorrer das semanas, principalmente pelo microfone.

Apesar das tecnologias de educação a distância estarem presentes há tanto nos ambientes de ensino, a necessidade de transição instantânea acelerou a adoção do ensino remoto emergencial para modalidades ainda presenciais e enfatizou a necessidade de programas de formação e atualização docente institucional. Ademais, o planejamento não pode ser discutido sem tempo e, sim como uma técnica de experimentação de tentativa e erro, além do conhecimento compartilhado em experiências alheias.

\section{REFERÊNCIAS}

APPENZELLER, Simone et al. Novos tempos, novos desafios: Estratégias para equidade de acesso ao Ensino Remoto Emergencial. Revista Brasileira de Educação Médica, Brasília, v. 44, supl. 1, 2020. 
ANJOS, Alexandre M. Tecnologias da informação e da comunicação, aprendizado eletrônico e ambientes virtuais de aprendizagem. In: MACIEL, Cristiano (Org.).

Ambientes virtuais de aprendizagem. Cuiabá: EdUFMT, 2012.

BAZANI, Camila L.; MIRANDA, Aline B. Planejamento no ensino superior. In: MIRANDA, Gilberto J.; LEAL, Edvalda A.; CASA NOVA, Silvia P. C. (Org.). Revolucionando a docência universitária: orientações, experiências e teorias para a prática docente em negócios. 1. ed. São Paulo: Atlas, 2018.

BLAUTH, Ivana F; DIAS, Nelson; SCHERER, Suely. Whatsapp como ambiente de interações na educação a distância: ensaios de encontros síncronos e assíncronos. HOLOS, v.6, 2019.

ELMOR FILHO, Gabriel et al. Uma nova sala de aula é possível: Aprendizagem ativa na educação em engenharia. 1. ed. Rio de Janeiro: Editora LTC, 2019.

FONTES, Adriana da S et al. Contribuições da plataforma digital Kahoot para o ensino. In: Congresso Internacional de Educação em Tecnologias, 2020, Evento On-Line. Disponível em https://cietenped.ufscar.br/submissao/index.php/2020/article/view/1082/789. Acesso em: 08. mai. 2021.

FUCKNER, Malton O. Prós e contras do ensino remoto: um estudo de caso do projeto conexão. Revista Docent Discunt, São Paulo, v. 1, n. 2, p. 128-145, 2020.

MACHADO, Leonardo C. Análise das mudanças na disciplina do PPGEC da EPUSP "Sustentabilidade no ambiente construído" devido ao isolamento social causado pelo coronavírus. In: XLVIII Congresso Brasileiro de Educação em Engenharia, 2020, Evento On-line. Anais. Disponível em:

http://www.abenge.org.br/sis artigo doi.php?e=COBENGE\&a=20\&c=2829. Acesso em: 08 abr. 2021.

SANTOS JUNIOR, Verissimo B.; MONTEIRO, Jean C. da S. Educação e COVID-19: as tecnologias digitais mediando a aprendizagem em tempos de pandemia. Revista Encantar - educação, cultura e sociedade, Rio de janeiro, v. 2, p. 01-15, 2020.

MINISTÉRIO DA EDUCAÇÃO. Conselho Nacional de Educação. Parecer CNE/CP № 5, de 28 de abril de 2020. Reorganização do Calendário Escolar e da possibilidade de cômputo de atividades não presenciais para fins de cumprimento da carga horária mínima anual, em razão da Pandemia da COVID-19. Brasília, 2020. Disponível em: http://portal.mec.gov.br/index.php?option=com docman\&view=download\&alias=14511pcp005-20\&category slud=marco-2020-pdf\&ltemid=30192. Acesso em: 11 abr. 2020.

NOGUEIRA, Daniel R. et al. E agora José? Metodologias em tempos de crise: ventos da mudança ou tsunami on-line. In: NOGUEIRA, Daniel R. et al. (Org.). Revolucionando a sala de aula 2: novas metodologias ainda mais ativas. 1. ed. São Paulo: Atlas, 2020. p. 122.

RIO GRANDE DO NORTE, Secretaria de Estado da Saúde Pública. Decreto $\mathrm{n} \cong 29.524$, de 17 de março de 2020. Dispõe sobre medidas temporárias para o enfrentamento da 
situação de emergência em saúde pública provocada pelo novo Coronavírus (COVID-19). Diário Oficial do Estado do Rio Grande do Norte. Natal. 2020. Disponível em: http://diariooficial.rn.gov.br/dei/dorn3/docview.aspx?id jor $=00000001 \&$ data $=20200318 \& i d$ doc $=677489$. Acesso em: 25 abr. 2020.

SILVA, Joselma; GOULART, Ilsa C. V.; CABRAL, Giovanna R. Ensino remoto na educação superior: impactos na formação inicial docente. Revista Ibero-Americana de Estudos em Educação (RIAEE), Araraquara, v. 16. n. 2, p. 407-423, 2021.

YIN, Robert. K. Estudo de caso: planejamento e métodos. 5. ed. Porto Alegre: Bookman, 2015.

\title{
A REPORT OF REMOTE TEACHING EXPERIENCE DURING THE COVID-19 PANDEMIC: PLANNING AND EXECUTION
}

\begin{abstract}
The Coronavirus pandemic has imposed changes in all areas of society. Thus, education, at all levels, went through several decrees that, at first, suspended the face-toface activities and, later, were resumed in the remote mode. Thus, teachers, students and teaching environments went through a series of obstacles in order to reconcile the urgency of implementing the period, the absence of contingency plans and a pandemic reality. In this context, this article, with a qualitative approach, presents an account of remote teaching experience in a discipline of the Industrial Engineering course at the Federal Rural University of the Semi-Arid with a focus on the course plan of a curricular component and aspects experienced in the period. For this, the differences between Distance Education, remote teaching, planning variables and methodologies for remote teaching are presented. The report details the planning and execution of the discipline, explaining the preparation, the course plan, teaching tools used, virtual libraries, evaluation methods, synchronous and asynchronous moments. The positive aspects of the experience were the absence of locks, conducting an online technical visit and the practicality of correcting tests and tasks in the institutional system. On the other hand, the main difficulties were the overload of work for the teacher, the initial difficulty of adaptation with the absence of tables to illustrate the explanations and mainly the reduction of student participation over the weeks, mainly through the microphone.
\end{abstract}

Keywords: Remote Teaching. Experience report. Lesson planning. 